\title{
UDL and its implications in MOOC accessibility evaluation
}

\author{
Francisco Iniesto and Garron Hillaire
}

\section{I5.I Introduction}

Assessing the accessibility of online educational environments is not easy. As we scale up educational technologies like with Massive Open Online Courses (MOOCs), we may amplify the impact of (in)accessible designs (Martin, Salvatierra, \& González, 2016). With MOOCs, we reach more learners and need to consider the variability that comes with scale (Papathoma et al., 2020), as previously highlighted in this book (Chua, 2022; Conde Gafaro, 2022; Iniesto, McAndrew, Minocha \& Coughlan, 2022; Rizvi, Rienties, Kizilcec, \& Rogaten, 2022). While the challenges and opportunities online learning at scale faces in terms of accessibility are great, the support from educators and technical experts of the platforms that host such courses has historically been minimal (Sanchez-Gordon \& LujánMora, 2017).

As indicated in Chapter 9, Iniesto et al. (2022) implemented an accessibility audit to understand how to improve the accessibility in MOOCs for learners with accessibility needs from an expert evaluation perspective. The audit was conducted to help understand the current state of accessibility in MOOCs (Iniesto, 2020). The methodology in the audit combined accessibility evaluation methods across four main evaluation areas to compose four different checklists in a common heuristic evaluation approach: technical accessibility, user experience (UX), quality and learning design evaluations.

Universal Design for Learning (UDL) was selected for the learning design component because UDL offers benefits for both learners and educators in its implementation in higher education. The greatest benefits of UDL implementations are often experienced by those learners with accessibility needs. While implementing UDL there is a reduction in the need for and time required to arrange individual accommodations, it is a proactive design that supports a diverse accessibility needs, and it offers a greater opportunity to develop more self-aware and knowledgeable learners (CAST, 2018). UDL has a thorough development and widespread use in primary, secondary and further educational contexts worldwide and it is already included in the curricula at university level (e.g., Gronseth et al., 2019). UDL is used in educational international initiatives such as INCLUDE (The International Collaboratory for Leadership in Universally Designed Education) (Bracken \& 
Novak, 2019) and UDLL (Universal Design for Learning - License to Learn) (Griful-Freixenet, Struyven,Verstichele, \& Andries, 2017). The most recent Inclusion and Education report (UNESCO, 2020) assesses the progress towards Sustainable Development Goal 4 which ensures inclusive and equitable quality education and promote lifelong learning opportunities for all, drawing attention to all those excluded from education because of background or ability, naming UDL 16 times in the report.

Lifelong learning and opportunities to all provided thanks to the implementation of UDL in online learning embraces the open world learning theme as an enabler that empowers creating expert educators and learners who are critical of the learning resources and platforms. To support the long-term aim of developing learners as expert evaluators of their learning environments, we focus first on the development of a rubric to evaluate MOOCs based on the UDL guidelines. In Chapter 15, we detail the reflective process followed to update the UDL framework, designed for developing accessible educational resources, to an evaluation checklist for MOOCs and the implications this process has for extending the aim of UDL from creating expert learners to creating expert evaluators. While we do not believe UDL can be simplified solely to a checklist we view this as a tool that can help to close the loop between the intention of course designers with evaluations from learners. With that goal in mind, we report on adapting the UDL guidelines to an evaluation checklist, the authors of Chapter 15 computed inter-rater reliability using Cohen's Kappa to validate the checklist as an iterative process for improvement (Gwet, 2014).

\section{I5.2 UDL to evaluate MOOCs}

UDL offers a framework that considers how to design learning environments to develop expert learners, defined in this framework as resourceful and knowledgeable, strategic and goal-directed, purposeful and motivated (CAST, 2017). UDL favours the elimination of physical, sensory, affective, and cognitive barriers to access, learning, and participation of learners (Meyer, Rose, \& Gordon, 2014). It aims to use various teaching methods to remove barriers to learning (understood as anything that prevents learners from fully engaging in learning) and give all learners the same opportunity to achieve their learning goals. UDL is based on three principles, as further explained in Table 15.1:

1 Provide multiple means of engagement. Learners differ in how they may feel involved and motivated to learn. Therefore, it is necessary to offer options that reflect the interests of learners, strategies to face new tasks, choices for selfevaluation and reflection on their expectations.

2 Provide multiple means of representation. Learners vary in the way they perceive and understand the educational content. Therefore, it is necessary to offer different options to approach materials through various channels of perception, be it auditory, visual, or motor, so it is required to provide the information in a format that allows as much as possible to be adjusted by the learner. 
Table I5.I UDL Principles and guidelines

\begin{tabular}{|c|c|c|c|}
\hline & $\begin{array}{l}\text { Provide multiple } \\
\text { means of } \\
\text { engagement }\end{array}$ & $\begin{array}{l}\text { Provide multiple } \\
\text { means of } \\
\text { representation }\end{array}$ & $\begin{array}{l}\text { Provide multiple } \\
\text { means of action and } \\
\text { expression }\end{array}$ \\
\hline Access & $\begin{array}{l}\text { (7) Provide } \\
\text { options for } \\
\text { recruiting } \\
\text { interest }\end{array}$ & $\begin{array}{l}\text { (I) Provide options } \\
\text { for perception }\end{array}$ & $\begin{array}{l}\text { (4) Provide options } \\
\text { for physical } \\
\text { action }\end{array}$ \\
\hline Build & $\begin{array}{l}\text { (8) Provide } \\
\text { options for } \\
\text { sustaining effort } \\
\text { and persistence }\end{array}$ & $\begin{array}{l}\text { (2) Provide options } \\
\text { for language \& } \\
\text { symbols }\end{array}$ & $\begin{array}{l}\text { (5) Provide options } \\
\text { for expression \& } \\
\text { communication }\end{array}$ \\
\hline Internalise & $\begin{array}{l}\text { (9) Provide } \\
\text { options for } \\
\text { self-regulation }\end{array}$ & $\begin{array}{l}\text { (3) Provide options } \\
\text { for } \\
\text { comprehension }\end{array}$ & $\begin{array}{l}\text { (6) Provide options } \\
\text { for executive } \\
\text { functions }\end{array}$ \\
\hline Goal & $\begin{array}{l}\text { Purposeful and } \\
\text { motivated }\end{array}$ & $\begin{array}{l}\text { Resourceful and } \\
\text { knowledgeable }\end{array}$ & $\begin{array}{l}\text { Strategic and } \\
\text { goal-directed }\end{array}$ \\
\hline
\end{tabular}

Source: Adapted from CAST (2018).

3 Provide multiple means for action and expression. Learners differ in how they can work during learning and express what they know. It is necessary to offer varied options for action through materials with which all learners can interact, facilitate fluent opinions, and seek the stimulation of the effort and the motivation towards a goal.

Since the UDL Guidelines are meant to be informed by both new research and feedback from the field, they have been updated several times in the past. As indicated in Table 15.1, the guidelines start with the principle Provide multiple means of Engagement but originally it was Provide Multiple Means of Representation. While the principles were reordered the guidelines were not renumbered which is why guidelines 7-9 appear first in the framework. UDL has recently informed that guidelines are going to be updated again following a community-driven process (CAST, 2020).

The three design principles contain nine guidelines and 31 checkpoints. Principles outline the overall goal while the checkpoints provide specific design advice that considers accessibility and learning. In the most recent version of the UDL Guidelines (CAST, 2018), the guidelines and checkpoints have been further organised into access, build, and internalise categories. The "access" category includes guidelines that suggest ways to increase access to the learning goal by recruiting interest and by offering options for perception and physical action. The "build" category comprises guidelines that suggest ways to develop effort and persistence, language and symbols, and expression and communication. Finally, the "internalise" category incorporates guidelines that suggest ways to empower 
learners through self-regulation, comprehension, and executive function. Each one of them shows the maturing process to become an expert learner.

Therefore, the UDL approach is to present the information in ways that fit learners' needs, rather than requiring learners to adapt to the information (Rose \& Meyer, 2006). This is useful for those users with learning and attention difficulties because it allows them to interact with the materials in several different ways (Cook \& Rao, 2018). At the same time, UDL supports every learner to choose the best path for their learning. This approach is relevant to understand learners who may like the curriculum to adjust to their needs. As reported above, one of the objectives of UDL is not simply the mastery of content knowledge or new technologies, it is the mastery of the learning process where education should help turn novice learners into expert learners (CAST, 2017), which aligns itself with MOOCs pedagogical perspective where learners are expected to be self-directed in their learning (Conde Gafaro, 2022).

The framework proposed by UDL is intended to produce educational content following the principles of UDL rather than being evaluated once those resources are provided (Hall, Cohen, Vue, \& Ganley, 2015). However, UDL has been proved as an appropriate framework to categorise and address barriers to learning for online environments (Rao, Ok, Smith, Evmenova, \& Edyburn, 2020). Following the UDL objective to promote expert learners the process of using the UDL framework to evaluate MOOCs is an exercise to show the ability to evaluate the online environment for barriers to learning. Figure 15.1 shows that the process of the application of the framework as an evaluative framework for MOOCs is a support for those learning about technology accessibility and learning. Educators and learners can benefit from evaluating them in a process that facilities exploring their educational needs as expert evaluators (i.e., expert learners).

\subsection{The design and validation of the framework}

The design and validation of the framework fell into three phases. The first phase was the creation of the checklist by the first author. The second phase was reviewing the checklist with the UDL expert, in other words, the second author. Finally, the third phase involved an inter-rater reliability agreement protocol between both raters.

\subsection{Creating the framework}

The meta-framework proposed included four components (Iniesto, McAndrew, Minocha, \& Coughlan, 2019). The MOOC accessibility audit components are as follows:

1 Technical accessibility evaluation. Checking of conformance to guidelines through WCAG (2018) and the text-based files.

2 User experience (UX) evaluation. The evaluation of usability and UX characteristics of the user interface design and pedagogical design. 


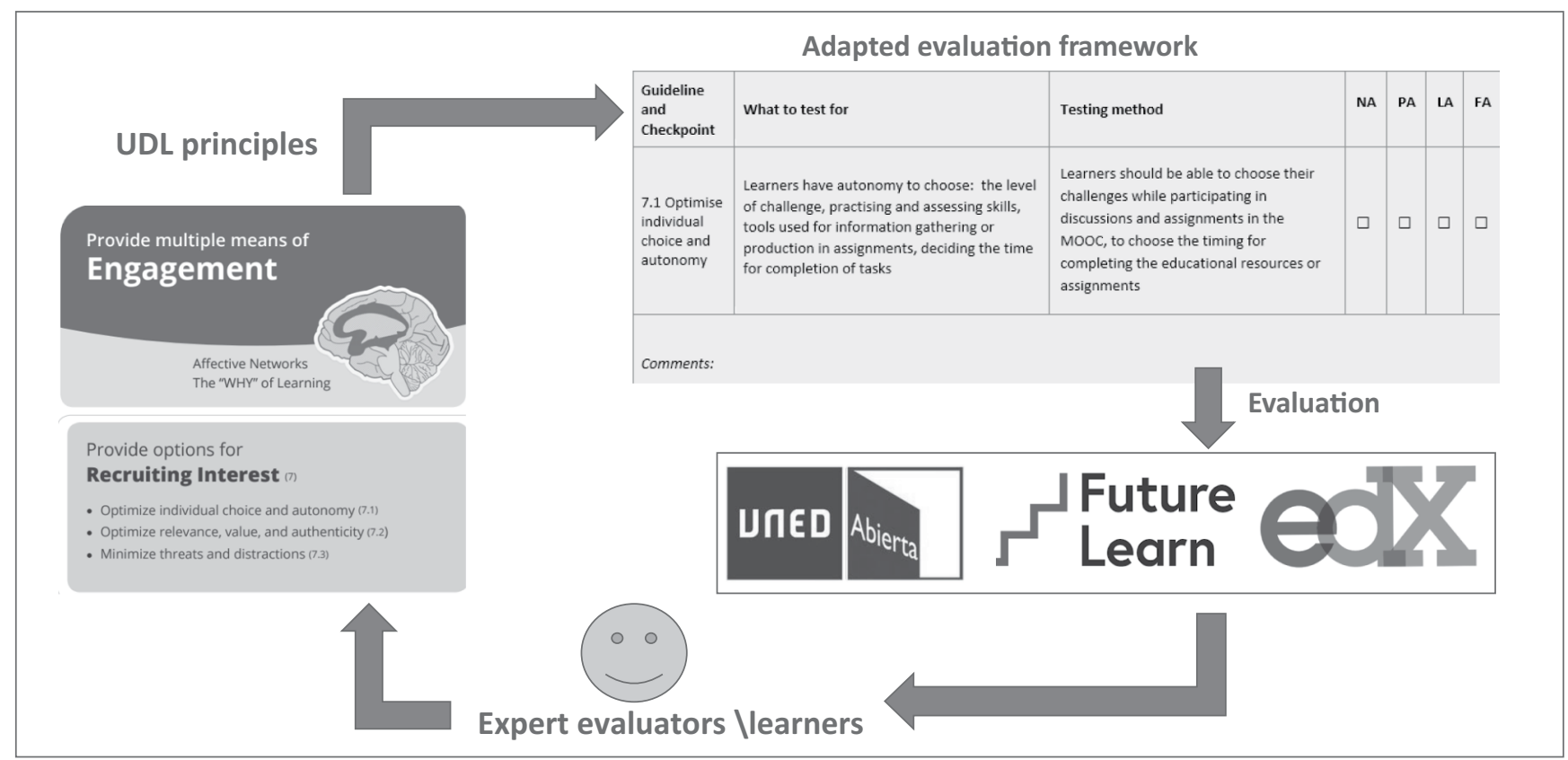

Figure 15./ UDL evaluation process. 
3 Quality evaluation. Evaluation of MOOCs properties, the quality of the design, platform, and support for learners.

4 Learning design evaluation. Evaluation of the learning design characteristics within MOOCs using UDL.

All of them share a standard set of characteristics: checklists were applied to evaluate the MOOC once it was run and had the same structure (principle, guideline, and criteria). Some further characteristics included:

- The checklist shares the same structure for every single criterion:

- What to test for: information to help the reviewer to know what the criterion is evaluating.

- Testing method: information to help the reviewer to proceed to test the criterion.

- Comments: space for the reviewer to add free comments.

- The checklist shares the same rating method:

- $\quad$ NA (Not achieved): The feature to test is missing.

- PA (Partially achieved): The feature to test is available but not integrated.

- LA (Largely achieved):The feature to test is available and partially integrated.

- $\quad$ FA (Fully achieved): The feature to test is available and fully integrated.

- If the criterion is not applicable, Not Applicable is added to the comments

The use of "What to test" for and "Testing method" was based on the accessibility heuristic evaluation template by the Inclusive Design Research Centre (Pererya, 2016). The four evaluation criteria were taken from the OpenUpEd quality label benchmark (Rosewell \& Jansen, 2014). As Brajnik, Yesilada, and Harper (2010) claimed, heuristic evaluations can be complex and even produce wrong results (false positives). For that reason, a good definition of what should be evaluated and how the evaluation should be carried out has been developed to help the evaluator. In the "Testing method" the explanation provided aims to reinforce what a fully achieved item would be. Developing a rating system that has four different values seeks to avoid a system that considers that a criterion is only fulfilled or not fulfilled, by adding the nuance that a criterion can be partially or largely implemented, in addition the use of comments allows the opinion of the evaluator to be explained to enrich the feedback available.

In the case of the learning design component reported in Chapter 15 the first author produced a draft for each of the 31 UDL checklists, named criteria in the audit. The design of the criteria for this component required a completely new development in the sections "What to test for" and "Testing method". For that purpose, the first author used UDL examples proposed by CAST, which helped to prepare specific cases in MOOCs (CAST, 2016).

\subsubsection{Designing the framework}

The design and validation processes between the two authors included a total of five meetings (Figure 15.2). That had two aims: improving the component 


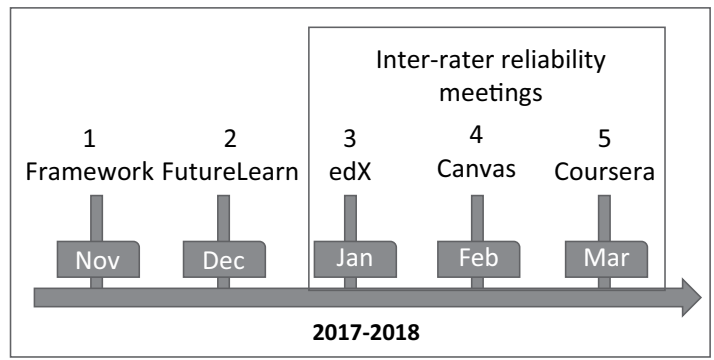

Figure /5.2 Design and validation meetings.

specifications iteratively and training to be critical using UDL (i.e., become an expert evaluator). Therefore, it was an iterative process between the two authors, whereby the second author acted as the rater for the validation of the design. The two initial meetings served different purposes: the first meeting had the objective of setting the evaluation framework reviewing the checklist proposal. The second meeting was used to carry out a process of testing the checklist on a MOOC of FutureLearn (Table 15.2). The sample for the validation process for the three remaining meetings included MOOCs from Coursera, edX and Canvas. The reason for the four differentiated platforms was to enrich the sample since different providers have different MOOC offering and pedagogical designs, as well all MOOCs cover differentiated subjects to allow finding varied barriers to learning.

\subsubsection{Validating the application of the framework}

In each of the validation meetings, the content of "what to test for" and "testing method" sections of the criteria were reviewed and improved to evolve from general testing to MOOCs structure. The updated version was used in the next evaluation. Figure 15.3 shows the evolution of criteria 9.1 and 2.2 as examples from meetings 4 to 5 (final version).

To allow validation of the framework, inter-rater reliability was computed. Inter-rater reliability, also known as inter-rater agreement, applies a score of how much consensus there is in the ratings given by various raters to test validity (Hallgren, 2012). Inter-rater reliability is useful in processes to determine if a scale is appropriate for measuring a variable. In the case of rater disagreement, it need not follow that the scale proposed is defective but that, for example, the raters need more training and better requirements (i.e., the process of becoming an expert evaluator through the improvement of the evaluation framework).

The inter-rater reliability protocol followed a systematised process that included two steps per inter-rater reliability meeting. The first step consisted of a brief talk before the individual evaluation to agree on the checklist version to be used and the course sample (i.e., webpages and educational resources from the platform and course) were understood by the raters. In the second step, the results of the 
Table 15.2 Sample for the validation process

\begin{tabular}{|c|c|c|c|c|c|}
\hline Order & Platform provider & MOOC & Course provider & Subject & Validated \\
\hline $\begin{array}{l}1 \\
2\end{array}$ & $\begin{array}{l}\text { FutureLearn } \\
\text { edX }\end{array}$ & $\begin{array}{l}\text { Smart Cities } \\
\text { Introduction to Computational } \\
\text { Thinking and Data Science }\end{array}$ & $\begin{array}{l}\text { The Open University } \\
\text { MIT }\end{array}$ & $\begin{array}{l}\text { Engineering } \\
\text { Mathematical } \\
\text { Sciences }\end{array}$ & $\begin{array}{l}\text { No } \\
\text { Yes }\end{array}$ \\
\hline 3 & Canvas & $\begin{array}{l}\text { Biometric Technologies: } \\
\text { Identification for the Future }\end{array}$ & $\begin{array}{l}\text { Canberra Institute of } \\
\text { Technology }\end{array}$ & Biological sciences & Yes \\
\hline 4 & Coursera & $\begin{array}{l}\text { Learning How to Learn: } \\
\text { Powerful mental tools to help } \\
\text { you master tough subjects }\end{array}$ & University of California & Education & Yes \\
\hline
\end{tabular}

Source: Adapted from Iniesto (2020). 


\begin{tabular}{|c|c|c|}
\hline $\begin{array}{l}\text { 9.1 Promote expectations } \\
\text { and beliefs that optimise } \\
\text { motivation }\end{array}$ & $\begin{array}{l}\text { 1. In test and quizzes, you can find feedback depending } \\
\text { on your answers that helps learner } \\
\text { 2. There are examples to show variable goals that can be } \\
\text { achieved for learners with different strengths and } \\
\text { weaknesses } \\
\text { 3. The learner can reflect by himself in a private space to } \\
\text { take notes or discuss with a single peer in privacy }\end{array}$ & $\begin{array}{l}\text { Test and quizzes provide automated feedback, as well, } \\
\text { there are examples to show variable goals that can be } \\
\text { achieved for learners with different strengths and } \\
\text { weaknesses, learners can reflect in private space to take } \\
\text { notes or discuss with another learner with privacy (one to } \\
\text { one) }\end{array}$ \\
\hline $\begin{array}{l}2.2 \text { Clarify syntax and } \\
\text { structure }\end{array}$ & $\begin{array}{l}\text { 1. The structure of the MOOC every week is similar and } \\
\text { keeps the same style and structure, keeping } \\
\text { consistency with the terminology } \\
\text { 2. At the beginning of the week there are connections to } \\
\text { the previous weeks content and activities }\end{array}$ & $\begin{array}{l}\text { The structure of the MOOC content is similar and keeps } \\
\text { the same style and structure, keeping consistency with the } \\
\text { terminology. The content delivered is consistent across the } \\
\text { course modules (e.g. using the same syntax for concepts } \\
\text { like multiplication across the module) }\end{array}$ \\
\hline
\end{tabular}

Figure 15.3 UDL checklists / Learning design criteria testing method evolution.

evaluation and possible improvements were discussed. In case of discrepancy, an agreement was then reached between the evaluators on how that particular criterion should be qualified (Cook et al., 2009).

The terminology that describes the agreement process includes:

- $\quad$ Success and failure. Success criteria are considered fully achieved (FA) and largely achieved (LA), failure criteria are considered partially achieved (PA) and not achieved (NA).

- Agreement. Evaluators can agree that is either perfect agreement or moderate agreement.

- Perfect agreement. A perfect agreement is considered when the evaluators gave the same rating to a criterion (e.g., FA vs FA, NA vs NA).

- Moderate agreement. Moderated agreement is when the rating given by the evaluators differs within the same group (success or failure).

- Disagreement. The rating between the evaluators differed between success or failure (e.g., PA vs FA or NA vs FA).

- $\quad$ Final agreement. The final rating as discussed and agreed.

We included statistical mathematical agreement using Cohen's Kappa $(\mathrm{k})$ when examining the agreement between two raters (0.01-0.20 slight agreement, 0.210.40 fair agreement, $0.41-0.60$ moderate agreement, $0.61-0.80$ substantial agreement and 0.81-1.00 perfect agreement) (Gwet, 2014).

The edX agreement was of 24 out of 31 , with 10 full agreements $(\mathrm{k}=0.55)$. With Canvas there was a consensus of 24 out of 31,11 of full agreement $(k=0.55)$. Finally, with Coursera, there was a concurrence of 26 out of 31,12 of the criteria with full agreement $(k=0.59)$ (Table 15.3). Overall, the results indicated that the level of agreement increased during the third round of evaluation. In all cases, for the full evaluation process Cohen's Kappa showed a moderate agreement. When looking at the principles there were agreement fluctuations even when the specifications of the criteria included in the checklists were improved at each iteration. As well, there was variation at the criteria level in each iteration, which might be due 
Table 15.3 Cohen's Kappa between evaluators

\begin{tabular}{llccc}
\hline & Engagement & Representation & $\begin{array}{c}\text { Action and } \\
\text { expression }\end{array}$ & Full evaluation process \\
\hline edX & 0.28 & 0.83 & 0.57 & 0.55 \\
Canvas & 0.19 & 0.47 & 0.57 & 0.55 \\
Coursera & 0.8 & 0.42 & 0.39 & 0.59 \\
\hline
\end{tabular}

to the nature of the sample, with different MOOCs and providers, and the richness of specifications in the UDL criteria.

To understand where the raters were improving their agreement and areas where it was more difficult, we further disaggregated the analysis at the principle level. Tables 15.4, 15.5 and 15.6 show the agreements and disagreements including both moderate agreements and final agreement. These tables are helpful to show visually the discrepancies during the process. Only one criterion of the 31 had not incurred any discrepancies ("Use multiple tools for construction and composition", 5.2), which exemplified the different interpretations that can be made while learning how to internalise UDL. Highlighted disagreements in the following explanations included those who have appeared in two or more evaluations.

For the principle "means of engagement" (Table 15.4), those criteria where there had been a substantial discrepancy were:

- "Optimise individual choice and autonomy" (7.1) and "Optimise relevance, value, and authenticity" (7.2). It was difficult to evaluate if learners can choose their challenges while participating in discussions and assignments and if those allow learners to connect with their learning goals.

- "Foster collaboration and community" (8.3). Difficulties when evaluating arose to determine if learners can find support to foster collaboration to encourage discussions.

- "Facilitate personal coping skills and strategies" (9.2). In a MOOC environment, it was not straightforward to identify places for learners to identify coping skills in discussions, either originated by facilitators or learners themselves.

Therefore, in MOOCs it is difficult to evaluate the engagement between learners and educators (and learners themselves) in discussions and assignments, an aspect reported both in the literature (Bote-Lorenzo \& Gómez-Sánchez, 2017) and in this book (Chua, 2022; Conde Gafaro, 2022; Rizvi et al., 2022), losing part of the MOOC claimed support for social interaction (Sunar, White, Abdullah \& Davis, 2016).

In the case of "means of representation" (Table 15.5), at criteria level key disagreements were:

- "Highlight patterns, critical features, big ideas, and relationships" (3.2) and "Maximise transfer and generalisation" (3.4). It was not easy to identify examples of essential features, places where having previous knowledge could help. As well, the existence of tools for the learners to personalise and generalise their learning. 
Table 15.4 Agreement process for "provide multiple means of engagement"

\begin{tabular}{|c|c|c|c|c|c|c|c|c|c|}
\hline \multirow[t]{2}{*}{ Criteria \ checklists } & \multicolumn{3}{|l|}{ edX } & \multicolumn{3}{|c|}{ Canvas } & \multicolumn{3}{|c|}{ Coursera } \\
\hline & $R I$ & $R 2$ & $F A$ & $R I$ & $R 2$ & $F A$ & $R I$ & $R 2$ & $F A$ \\
\hline $\begin{array}{l}\text { 7.1 Optimise individual choice and autonomy } \\
\text { 7.2 Optimise relevance, value, and authenticity } \\
\text { 7.3 Minimise threats and distractions } \\
\text { 8.1 Heighten salience of goals and objectives } \\
\text { 8.2 Vary demands and resources to optimise challenge } \\
\text { 8.3 Foster collaboration and community } \\
\text { 8.4 Increase mastery-oriented feedback } \\
\text { 9.1 Promote expectations and beliefs that optimise motivation } \\
\text { 9.2 Facilitate personal coping skills and strategies } \\
\text { 9.3 Develop self-assessment and reflection }\end{array}$ & $\begin{array}{l}\text { PA } \\
\text { LA } \\
\text { LA } \\
\text { PA } \\
\text { NA } \\
\text { LA } \\
\text { NA } \\
\text { PA } \\
\text { LA } \\
\text { PA }\end{array}$ & $\begin{array}{l}\text { NA } \\
\text { PA } \\
\text { LA } \\
\text { NA } \\
\text { NA } \\
\text { NA } \\
\text { NA } \\
\text { NA } \\
\text { NA } \\
\text { NA }\end{array}$ & $\begin{array}{l}\text { NA } \\
\text { PA } \\
\text { LA } \\
\text { NA } \\
\text { NA } \\
\text { PA } \\
\text { NA } \\
\text { PA } \\
\text { PA } \\
\text { PA }\end{array}$ & $\begin{array}{l}\text { LA } \\
\text { LA } \\
\text { LA } \\
\text { PA } \\
\text { NA } \\
\text { LA } \\
\text { FA } \\
\text { LA } \\
\text { LA } \\
\text { PA }\end{array}$ & $\begin{array}{l}\text { NA } \\
\text { PA } \\
\text { LA } \\
\text { PA } \\
\text { PA }\end{array}$ & $\begin{array}{l}\text { PA } \\
\text { PA } \\
\text { LA } \\
\text { NA } \\
\text { LA } \\
\text { LA } \\
\text { PA } \\
\text { PA }\end{array}$ & $\begin{array}{l}\text { PA } \\
\text { FA } \\
\text { LA } \\
\text { PA } \\
\text { LA } \\
\text { LA } \\
\text { FA } \\
\text { PA } \\
\text { PA } \\
\text { NA }\end{array}$ & $\begin{array}{l}\text { LA } \\
\text { LA } \\
\text { LA } \\
\text { FA } \\
\text { FA } \\
\text { NA }\end{array}$ & $\begin{array}{l}\text { LA } \\
\text { LA } \\
\text { NA }\end{array}$ \\
\hline
\end{tabular}

Note: $\mathrm{R}$ I = Rater I; R2 = Rater2; FA = Final Agreement; NA = Not Achieved; PA = Partially Achieved; LA = Largely Achieved; FA = Fully Achieved.

Source: Adapted from Iniesto (2020). 
Table 15.5 Agreement process for "provide multiple means of representation"

\begin{tabular}{|c|c|c|c|c|c|c|c|c|c|}
\hline \multirow[t]{2}{*}{ Criteria \ checklists } & \multicolumn{3}{|l|}{ edX } & \multicolumn{3}{|c|}{ Canvas } & \multicolumn{3}{|c|}{ Coursera } \\
\hline & $R I$ & $R 2$ & $F A$ & $R I$ & $R 2$ & $F A$ & RI & $R 2$ & $F A$ \\
\hline $\begin{array}{l}\text { 1.I Offer ways of customising the display of information } \\
\text { 1.2 Offer alternatives for auditory information } \\
\text { 1.3 Offer alternatives for visual information } \\
\text { 2.1 Clarify vocabulary and symbols } \\
\text { 2.2 Clarify syntax and structure } \\
\text { 2.3 Support decoding of text, mathematical notation, and symbols } \\
\text { 2.4 Promote understanding across languages } \\
\text { 2.5 Illustrate through multiple media } \\
\text { 3.I Activate or supply background knowledge } \\
\text { 3.2 Highlight patterns, critical features, big ideas, and relationships } \\
\text { 3.3 Guide information processing, visualisation, and manipulation } \\
\text { 3.4 Maximise transfer and generalisation }\end{array}$ & $\begin{array}{l}\text { LA } \\
\text { FA } \\
\text { PA } \\
\text { PA } \\
\text { FA } \\
\text { PA } \\
\text { PA } \\
\text { NA } \\
\text { PA } \\
\text { FA } \\
\text { LA } \\
\text { FA }\end{array}$ & $\begin{array}{l}\text { FA } \\
\text { LA } \\
\text { PA } \\
\text { NA } \\
\text { LA } \\
\text { NA } \\
\text { NA } \\
\text { PA } \\
\text { PA } \\
\text { PA }\end{array}$ & $\begin{array}{l}\text { LA } \\
\text { LA } \\
\text { PA } \\
\text { NA } \\
\text { LA } \\
\text { NA } \\
\text { PA } \\
\text { PA } \\
\text { PA } \\
\text { PA }\end{array}$ & $\begin{array}{l}\text { PA } \\
\text { PA } \\
\text { NA } \\
\text { NA } \\
\text { PA } \\
\text { Not } \\
\text { PA } \\
\text { LA } \\
\text { LA } \\
\text { LA } \\
\text { FA } \\
\text { LA }\end{array}$ & NA & $\begin{array}{l}\text { e } \\
\text { PA } \\
\text { PA }\end{array}$ & $\begin{array}{l}\text { PA } \\
\text { LA } \\
\text { LA } \\
\text { LA } \\
\text { LA } \\
\text { Not } \\
\text { FA } \\
\text { PA } \\
\text { LA } \\
\text { FA } \\
\text { FA } \\
\text { PA }\end{array}$ & $\begin{array}{l}\text { LA } \\
\text { FA } \\
\text { FA } \\
\text { FA } \\
\text { FA } \\
\text { oplicable } \\
\text { LA } \\
\text { LA } \\
\text { FA } \\
\text { LA } \\
\text { LA }\end{array}$ & $\begin{array}{l}\text { PA } \\
\text { LA } \\
\text { LA } \\
\text { LA } \\
\text { LA } \\
\text { LA } \\
\text { PA } \\
\text { LA } \\
\text { LA } \\
\text { LA }\end{array}$ \\
\hline
\end{tabular}

Source: Adapted from Iniesto (2020). 
Table 15.6 Agreement process for "provide multiple means of action and expression"

\begin{tabular}{|c|c|c|c|c|c|c|c|c|c|}
\hline \multirow[t]{2}{*}{ Criteria \ checklists } & \multicolumn{3}{|c|}{ edX } & \multicolumn{3}{|c|}{ Canvas } & \multicolumn{3}{|c|}{ Coursera } \\
\hline & $R I$ & $R 2$ & $F A$ & $R I$ & $R 2$ & $F A$ & $R I$ & $R 2$ & $F A$ \\
\hline \multirow{3}{*}{$\begin{array}{l}\text { 4.I Vary the methods for response and navigation } \\
\text { 4.2 Optimise access to tools and assistive technologies } \\
\text { 5.I Use multiple media for communication } \\
\text { 5.2 Use multiple tools for construction and composition } \\
\text { 5.3 Build fluencies with graduated levels of support for practice and } \\
\text { performance } \\
\text { 6.I Guide appropriate goal-setting } \\
\text { 6.2 Support planning and strategy development } \\
\text { 6.3 Facilitate managing information and resources } \\
\text { 6.4 Enhance capacity for monitoring progress }\end{array}$} & $\begin{array}{l}\text { LA } \\
\text { LA } \\
\text { LA } \\
\text { LA }\end{array}$ & NA & PA & $\begin{array}{l}\text { FA } \\
\text { FA } \\
\text { LA } \\
\text { PA }\end{array}$ & $\begin{array}{l}\text { LA } \\
\text { LA }\end{array}$ & $\begin{array}{l}\text { LA } \\
\text { LA }\end{array}$ & $\begin{array}{l}\text { NA } \\
\text { NA } \\
\text { PA } \\
\text { PA }\end{array}$ & $\begin{array}{l}\text { LA } \\
\text { NA }\end{array}$ & $\begin{array}{l}\text { PA } \\
\text { PA }\end{array}$ \\
\hline & PA & NA & NA & LA & PA & PA & PA & & \\
\hline & $\begin{array}{l}\text { LA } \\
\text { NA } \\
\text { PA } \\
\text { PA }\end{array}$ & $\begin{array}{l}\text { NA } \\
\text { NA }\end{array}$ & $\begin{array}{l}\text { PA } \\
\text { PA }\end{array}$ & $\begin{array}{l}\text { PA } \\
\text { NA } \\
\text { NA } \\
\text { LA }\end{array}$ & PA & PA & $\begin{array}{l}\text { PA } \\
\text { NA } \\
\text { NA } \\
\text { LA }\end{array}$ & $\begin{array}{l}\text { NA } \\
\text { LA } \\
\text { PA }\end{array}$ & $\begin{array}{l}\text { PA } \\
\text { LA } \\
\text { PA }\end{array}$ \\
\hline
\end{tabular}

Source:Adapted from Iniesto (2020). 
In MOOCs information about prior knowledge should be clear before enrolment and there should exist pointers to external resources during the course. As well, there is a lack of possibilities for personalisation, something that is problematic at the platform level since it affects courses even if they have been designed allowing space for personalising the learner experience (García-Peñalvo, Fidalgo-Blanco, \& Sein-Echaluce, 2018). Finally, for "means of action and expression" principle (Table 15.6), criteria showed disagreements at some stage, but they were not repeated across the several evaluations.

The fact that the "means of engagement" principle accumulated more disagreements than "means of representation" but still more than "means of action and expression" pointed towards engagement complexities in MOOCs. Expert learners in MOOCs are often strategic and goal-directed, therefore, they are good at self-directed learning (Watted \& Barak, 2018), but do worse in being purposeful and motivated, which is aligned with the drop-out rates and difficulties to keep the engagement in MOOCs (Petronzi \& Hadi, 2016).

\section{5.4 Discussion and moving forwards}

In Chapter 15 we have reported on the adaptation of the UDL framework for evaluation purposes following an inter-rater reliability validation process. UDL evaluation processes by educators and learners facilitate the empowerment of creating expert learners who are critically evaluating the educational platforms and resources. Discussions during the validation process between the two raters included multiple conversations on what to evaluate in MOOCs using the UDL framework. In that sense, one of the principal difficulties was to distinguish whether the requirements should be addressed at platform or course level. This aspect is identified where the reliability agreements were lower which is underpinning differences between the platforms $s$ and their individual features for hosting educational resources and underlying pedagogical models. That aspect is linked with the lack of specification of MOOC completion and inclusion of discussions in educational resources, the lack of options to optimise individual choice and ways of customising the display of information. Aspects already reported in the broader literature of learning at scale in MOOCs (Joksimovic et al., 2018).

A key aspect of the UDL checklist after its validation was its complexity. Criteria in the UDL checklist were often rich, covering multiple aspects to be evaluated, which made it complicated for an evaluator to decide a final rating. That was linked with the fact of the complexity of acquiring expertise in UDL, and therefore an expert evaluator through the MOOC evaluation process. Future evaluations should consider including more MOOCs per platform provider, and more platforms, to understand the different evaluations between course providers using the same platform. In a broader context, further research in learning design and accessibility in MOOCs should also consider other aspects such as the role of learning analytics to understand the diversity of learners needs (Cooper, Ferguson, \& Wolff, 2016), how learner-emotions affect learning (Hillaire, Iniesto, \& Rienties, 2019) and how personalisation informs the learning process and engagement (FitzGerald et al., 2018). 
The process in Chapter 15 has shown that UDL cannot be stored in a box and applied as a simple checklist. The design and validation of evaluation checklists indicate a complexity of learning, whereby different concepts derived from the UDL framework proposed and how practising in this iterative evaluation and validation process helps to internalise UDL principles and guidelines. But as well showcasing the appearance of complex concepts to evaluate or redundancies that might be creating difficulties in that mastering process.

\subsection{Implications for practice}

When producing educational resources all stakeholders should be considered in their design and evaluation processes including educators and learners. To all those educators interested in universal and inclusive design, reflecting on the UDL principles and guidelines may help when producing educational resources and critically evaluating them, which may facilitate and foster inclusion and widen access. To make online courses more accessible it is necessary to put in place processes to identify barriers to learning and strengthen mechanisms that facilitate agile responses in addressing those barriers. Regardless of whether to design MOOCs or any other online course, it is necessary to consider the different platforms that exist and how their pedagogical designs influence our decisions. In this sense, they can affect aspects of UDL such as the production of educational resources in alternative formats, the promotion of interaction and engagement between learners or the inclusion of space to allow reflection and personalisation of the learning experience.

\section{References}

Bote-Lorenzo, M. L., \& Gómez-Sánchez, E. (2017). Predicting the decrease of engagement indicators in a MOOC. In A. Wise, P.H. Wine, \& G. Lynch (Eds.), Proceedings of the seventh international learning analytics \& knowledge conference (pp. 143-147). Association for Computing Machinery.

Bracken, S., \& Novak, K. (Eds.). (2019). Transforming higher education through universal design for learning: an international perspective. London and New York: Routledge.

Brajnik, G.,Yesilada,Y., \& Harper, S. (2010). Testability and validity of WCAG 2.0: the expertise effect. In A. Barreto \& V. Hanson (Eds.), Proceedings of the 12th international ACM SIGACCESS conference on computers and accessibility (pp. 43-50). Association for Computing Machinery.

CAST. (2016). UDL tips for designing an engaging learning environment. http://www.cast.org/ publications/2016/udl-tips-designing-engaging-learning-environment

CAST. (2017). Top 5 UDL tips for fostering expert learners. https://www.learningdesigned.org/ resource/top-5-udl-tips-fostering-expert-learners

CAST. (2018). Universal Design for Learning Guidelines version 2.2. http://udlguidelines.cast.org

CAST. (2020). CAST announces a community-driven process to update UDL guidelines. https:// www.cast.org/news/2020/community-driven-process-update-udl-guidelines

Chua, S. M. (2022). Discourse practices in MOOC discussions: a corpus linguistic approach. In B. Rienties, R. Hampel, E. Scanlon, \& D. Whitelock (Eds.), Open world learning: research, innovation and the challenges of high-quality education (pp. 76-88). London: Routledge. 
Conde Gafaro, B. (2022). First steps towards self-regulated learning: setting goals in MOOCs. In B. Rienties, R. Hampel, E. Scanlon, \& D. Whitelock (Eds.), Open world learning: research, innovation and the challenges of high-quality education (pp. 63-75). London: Routledge.

Cook, D. A., Dupras, D. M., Beckman, T. J., Thomas, K. G., \& Pankratz,V. S. (2009). Effect of rater training on reliability and accuracy of mini-CEX scores: a randomized, controlled trial. Journal of General Internal Medicine, 24(1), 74.

Cook, S. C., \& Rao, K. (2018). Systematically applying UDL to effective practices for students with learning disabilities. Learning Disability Quarterly, 41(3), 179-191.

Cooper, M., Ferguson, R., \& Wolff, A. (2016). What can analytics contribute to accessibility in e-learning systems and to disabled students' learning? In D. Gasevic \& G Lynch (Eds.), Proceedings of the Sixth International Conference on Learning Analytics \& Knowledge (pp. 99103). Association for Computing Machinery.

FitzGerald, E., Kucirkova, N., Jones, A., Cross, S., Ferguson, R., Herodotou, C., Hillaire, G. \& Scanlon, E. (2018). Dimensions of personalisation in technology-enhanced learning: a framework and implications for design. British Journal of Educational Technology, 49(1), 165-181.

García-Peñalvo, F. J., Fidalgo-Blanco, Á., \& Sein-Echaluce, M. L. (2018). An adaptive hybrid MOOC model: disrupting the MOOC concept in higher education. Telematics and Informatics, 35(4), 1018-1030.

Griful-Freixenet, J., Struyven, K., Verstichele, M., \& Andries, C. (2017). Higher education students with disabilities speaking out: perceived barriers and opportunities of the Universal Design for Learning framework. Disability \& Society, 32(10), 1627-1649.

Gronseth, S., Dalton, E., Khanna, R., Alvarez, B., Iglesias, I., Vergara, P., Ingle, J. C., PachecoGuffrey, H., Bauder, D., \& Cooper, K. (2019). Inclusive instructional design and UDL around the world. In Society for Information Technology \& Teacher Education International Conference (pp. 2357-2359).

Gwet, K. L. (2014). Handbook of inter-rater reliability: the definitive guide to measuring the extent of agreement among raters. Gaithersburg, USA: Advanced Analytics, LLC.

Hall,T. E., Cohen, N.,Vue, G., \& Ganley, P. (2015). Addressing learning disabilities with UDL and technology: strategic reader. Learning Disability Quarterly, 38(2), 72-83.

Hallgren, K. A. (2012). Computing inter-rater reliability for observational data: an overview and tutorial. Tutorials in Quantitative Methods for Psychology, 8(1), 23.

Hillaire, G., Iniesto, F., \& Rienties, B. (2019). Humanising text-to-speech through emotional expression in online courses. Journal of Interactive Media in Education, 1, 12.

Iniesto, F. (2020). An investigation into the accessibility of massive open online courses (MOOCs) (Doctoral dissertation, The Open University). http://oro.open.ac.uk/70010/

Iniesto, F, McAndrew, P., Minocha, S., \& Coughlan, T. (2019). Auditing the accessibility of MOOCs: a four-component approach. In European Conference on Technology Enhanced Learning (pp. 650-654). Cham: Springer.

Iniesto, F, McAndrew, P., Minocha, S., \& Coughlan, T. (2022). Accessibility in MOOCs: the stakeholders' perspectives. In B. Rienties, R. Hampel, E. Scanlon, \& D. Whitelock (Eds.), Open world learning: research, innovation and the challenges of high-quality education (pp. 119130). London: Routledge.

Iniesto, F., Rodrigo, C. \& Hillaire, G. (2019). Applying UDL principles in an inclusive design project based on MOOCs reviews. Universal Access Through Inclusive Instructional Design: International Perspectives on UDL.

Joksimović, S., Poquet, O., Kovanović, V., Dowell, N., Mills, C., Gašević, D., Dawson, S., Graesser, A.C. and Brooks, C. (2018). How do we model learning at scale? A systematic review of research on MOOCs. Review of Educational Research, 88(1), 43-86. 
Martin, J. L., Salvatierra, H. A., \& González, J. R. H. (2016). MOOCs for all: evaluating the accessibility of top MOOC platforms. The International Journal of Engineering Education, 32(5), 2274-2283.

Meyer, A., Rose, D. H., \& Gordon, D.T. (2014). Universal design for learning: theory and practice. CAST Professional Publishing.

Papathoma, T., Ferguson, R., Iniesto, F., Rets, I.,Vogiatzis, D., \& Murphy,V. (2020). Guidance on how learning at scale can be made more accessible. In Proceedings of the Seventh ACM Conference on Learning@ Scale (pp. 289-292).

Pererya, D. (2016). Accessibility for different abilities: a report. Canadian Journal of Disability Studies, 5(1), 158-182.

Petronzi, D., \& Hadi, M. (2016). Exploring the factors associated with MOOC engagement, retention and the wider benefits for learners. European Journal of Open, Distance and E-learning, 19(2), 112-129.

Rao, K., Ok, M. W., Smith, S. J., Evmenova, A. S., \& Edyburn, D. (2020). Validation of the UDL reporting criteria with extant UDL research. Remedial and Special Education, 41(4), 219-230.

Rizvi, S., Rienties, B., Kizilcec, R., \& Rogaten, J. (2022). Culturally adaptive learning design: a mixed-method study of cross-cultural learning design preferences in MOOCs. In B. Rienties, R. Hampel, E. Scanlon, \& D. Whitelock (Eds.), Open world learning: research, innovation and the challenges of high-quality education (pp. 103-116). London: Routledge.

Rose, D. H., \& Meyer, A. (2006). The future is in the margins: the role of technology and disability in educational reform. In A practical reader in universal design for learning, (pp. 1337). Peabody, MA: Center for Applied Special Technology.

Rosewell, J. \& Jansen, D. (2014). The OpenupEd quality label: benchmarks for MOOCs. INNOQUAL: The International Journal for Innovation and Quality in Learning, 2(3), 88-100.

Sanchez-Gordon, S., \& Luján-Mora, S. (2017). Research challenges in accessible MOOCs: a systematic literature review 2008-2016. Universal Access in the Information Society, 1-15.

Sunar, A. S., White, S., Abdullah, N. A., \& Davis, H. C. (2016). How learners' interactions sustain engagement: a MOOC case study. IEEE Transactions on Learning Technologies, 10(4), 475-487.

United Nations Educational, Scientific and Cultural Organization (UNESCO). (2020). Global education monitoring report 2020: inclusion and education: all means all. https:// unesdoc.unesco.org/ark:/48223/pf0000373718

Watted, A., \& Barak, M. (2018). Motivating factors of MOOC completers: comparing between university-affiliated students and general participants. The Internet and Higher Education, 37, 11-20.

WCAG (2018) Web content accessibility guidelines (WCAG) overview. https://www.w3.org/ WAI/standards-guidelines/wcag/ 